\title{
Banks' Micro Enterprises Loan Credit Risk Decision-making Model Innovation in the Era of Big Data and Internet Finance
}

\author{
Junxuan $\mathrm{Zhu}^{1} \&$ Zhe Huang \\ ${ }^{1}$ School of Management, Shanghai University of Engineering Science, Shanghai, China \\ Correspondence: Zhe Huang, School of Management, Shanghai University of Engineering Science, Shanghai, China. \\ Tel: 86-185-0170-4697. E-mail: 18501704697@163.com
}

Received: April 11, 2014

Accepted: May 8, 2014

Online Published: May 12, 2014

doi:10.5430/jms.v5n2p63

URL: http://dx.doi.org/10.5430/jms.v5n2p63

\begin{abstract}
In the era of big data, Internet enterprises have initiated a new operation model named Internet finance and developed micro enterprises loan business, which bring great challenges to banks' traditional business undoubtedly. This article talks about how banks low the expense on the basis of setting a big data strategy, and innovate micro enterprises loan credit risk decision-making model to explore a new profit point of growth.
\end{abstract}

Keywords: big data, Internet finance, micro enterprise loan business, decision-making model

\section{Introduction}

With the gradual development of the Internet, human has stepped into the big data era. The U.S. government has listed the "big data strategy" under nation wills and declared data is defined as "new oil of the future". The scale and flexibility to utilize data and the ability to explain and apply data will become important parts of comprehensive national power. The possession and control of data will become another core asset of a country beyond land rights, sea power, air power. Using big data techniques to process and analyse valuable information in structured data and unstructured data effectively will drive innovation in business model and decision-making model.

In the financial field, the Internet companies use big data techniques to analyse customer credit state, conduct Internet financial business, bringing challenges to the traditional financial organization and prompting banks in China to implement innovation in credit risk decision-making model. For example, in the field of credit loan, in order to solve the financial difficulties of micro enterprises, Ali finance has initiated credit loan. Now credit loan even is open to its ordinary customers, indicating its proficiency in micro enterprises loan techiques and ability improvement in risk control.

Unlike traditional credit loan, the Internet enterprises collect customer data throughout the Internet at a lower cost, rather than depend credit on guarantees or mortgages, reducing the threshold of micro enterprises and simplifying the applying process. Facing the challenges from the Internet companies and considering the characteristics of micro-enterprises' high credit risk, banks should develop big data strategies to mine micro enterprises' credit state and carry out innovation of micro enterprises credit risk decision-making model, which are the key to profit growth. On the basis of big data, this article will join static and dynamic data together to build micro enterprise credit risk decision-making model for banks, showing big data's advantage in dynamic risk control.

\section{Indicators System of Micro Enterprises Credit Risk Decision-making Model under AHP Method}

\section{1 static Objective Credit Risk Indicators System}

Although the financial information which repersents historical information of micro enterprises may not be entirely accurate, but for most micro enterprises, financial information in judging the credit state of companies still have some reference value to some extent. As external users of financial statements, banks can mine the financial data, especially micro enterprises' operational ability, profitability, development ability, debt-paying ability indicators which offer reliable reference to credit qualification judgement.

\subsubsection{Operating Ability}

Operating ability is how micro enterprises use its assets to make a profit. Its three representative indicators are accounts receivable turnover, inventory turnover and fixed assets turnover. First, accounts receivable has a pivotal 
role in current assets and withdraw it timely will strengthen micro enterprises' ability to repay short-term loans. Secondly, inventories cover a large proportion of current assets, so inventory turnover has a great impact on current assets mobility, affecting micro enterprises' short-term debt-paying ability. Fixed assets turnover is mainly used to measure the utilization efficiency of plants, equipment and other fixed assets. The higher the ratio is, the higher utilization efficiency and management level of the fixed assets are. Particularly, if these indicators are lower than the average level when compared, the low operational efficiency may affect the company's profitability.

\subsubsection{Profitability Indicators}

Profitability is micro enterprises' ability to earn profit through normal business. Its three representative indicators are return on total assets and net profit margin and profit margin on net assets. First, the net profit margin reflects the level of sales revenue, only micro enterprises sell out products, then the earnings will be used to repay the loan. Secondly, the higher the return on total assets, the higher efficiency of the assets utilization is, indicating micro enterprises perform well in increasing revenue and saving cost. Besides, profit margin on net assets is a comprehensive way to measure profitability. Similarly, the comparison between current indicators and historical indicators or the comparison within industry are necessary for mastering micro enterprises profitability trend.

\subsubsection{Debt Paying Ability Indicators}

Micro enterprises depend the ability to repay short-term loan heavily on how fast the current assets will convert into cash, so banks can use the quick ratio and cash ratio to measure micro enterprises' short-term debt paying ability. In the current assets, if inventory is unsaleable, then it is hard to liquidate. The quick ratio which deletes inventory from current assets can be more accurate to measure short-term debt paying ability. Cash ratio reflects short-term debt paying ability directly.

Through long-term debt paying ability analysis, banks can mine micro enterprises' long-term debt paying ability, deciding whether to establish long-term cooperative relationships with micro enterprises. Asset-liability ratio of micro enterprises treats total assets as a material guarantee of total liability, showing the ability to use liquidation income to repay the loans.

\subsubsection{Development Ability Indicator}

Micro enterprises' development ability is how to expand the scale and strengthen the competence on the basis of survival. The development potential indicators should also be investigated by banks. The total assets growth and operating profit growth ratio can be used. The higher the growth rate of total assets, the faster the scale of total assets increase. Secondly, the operating profit growth ratio reflects dynamic change of micro enterprises.

Financial indicators system, as a static objective indicators system of micro enterprises credit risk decision-making, provides credit qualification state from four angles: operation ability,debt-paying ability, profitability, development ability. The disadvantages of the system is that it relies on historical data and static data. Therefore, banks should learn to apply big data to the dynamic risk decision-making. Try to mine micro enterprises' dynamic real-time data, which is also the innovation point of credit risk decision-making model for banks.

\subsection{Dynamic Subjective Internet Indicators}

In the era of Internet, mobile communication and e-commerce, micro enterprises' many transactions are conducted via the Internet. Through mining internet transaction data, for example, through customer evaluation system, banks can improve the dynamic risk decision-making level. Here banks can select trust degree, product and service quality as two indicators.

\section{1) Trust Degree}

If micro enterprises have high trust degree, it will bring customer loyalty and word of mouth effect, leading to increase in wealth accumulation and business amount. Trust degree includes direct trust (TD) and indirect trust (TI), Lijuan He in "the construction of China micro enterprises Credit Evaluation System in the environment of e-commerce" pointed out:

$$
\begin{gathered}
T_{D}=1-a^{p}(0<\mathrm{a}<1) \\
\mathrm{T}_{I}=\left\{\begin{array}{cc}
1-a^{p-n}, & p>n \\
0, & \text { otherwise }
\end{array}\right.
\end{gathered}
$$


Among them, "p" represents the number of successful experiences, "a" represents threshold level of trust degree, and " $n$ " represents the number of unsuccessful experiences. Wang Rui, WU Lifa in "a trust-based web service computing model" propose a trust degree weighted algorithm:

$$
T=\omega \cdot T_{D}+(1-\omega) \cdot \mathrm{T}_{I}
$$

Among them " $\omega$ " represents weight distribution.

These description show that trust degree can be measured in the big data environment. Models can be given, and banks' task is fully mining the trust-related data, such as the number of customers, the frequency of successful transaction.

\section{2) Product and Service Quality}

The quality of products and services reflect miro enterprises' reputation and the ability to remain invincible in the fierce market competition, so the quality of products and services is also reliable standard for credit judgement. From the perspective of e-commerce process, every customer usually evaluates micro enterprises' products and service after every transaction, banks can focus data mining on the customer evaluation system or data from the whole supply chain platform that micro enterprises' involve in, including structured data and unstructured data. In addition, banks can also create secondary indicators in product and service quality: product quality, product description fidelity, service attitude, after-sale service.

One of the advantages of the dynamic subjective Internet indicators system is that the real-time data update dynamically, for which banks can make accurate judgement about micro enterprises' credit risk state, reflecting the impact of big data on risk control.

Table 1. Credit risk decision-making indicator system for banks

\begin{tabular}{|c|c|c|c|}
\hline \multicolumn{4}{|c|}{ static objective credit risk indicators system } \\
\hline first class indicators & $\begin{array}{c}\text { weight } \\
\text { distribution }\end{array}$ & secondary indicators & $\begin{array}{c}\text { weight } \\
\text { distribution }\end{array}$ \\
\hline \multirow{3}{*}{ operational ability } & \multirow{3}{*}{$A 1$} & accounts receivable turnover & $B 1$ \\
\hline & & inventory turnover & $B 2$ \\
\hline & & fixed assets turnover & B3 \\
\hline \multirow{3}{*}{ profitability } & \multirow{3}{*}{$A 2$} & net profit margin & $B 4$ \\
\hline & & return on total assets & B5 \\
\hline & & profit margin on net assets & B6 \\
\hline \multirow{3}{*}{ debt-paying ability } & \multirow{3}{*}{$A 3$} & quick ratio & $B 7$ \\
\hline & & cash ratio & $B 8$ \\
\hline & & asset-liability ratio & $B 9$ \\
\hline \multirow{2}{*}{ development ability } & \multirow{2}{*}{$A 4$} & total assets growth & $B 10$ \\
\hline & & operating profit growth ratio & $B 11$ \\
\hline \multicolumn{4}{|c|}{ dynamic subjective Internet indicators system } \\
\hline first class indicators & $\begin{array}{c}\text { weight } \\
\text { distribution }\end{array}$ & secondary indicators & $\begin{array}{c}\text { weight } \\
\text { distribution }\end{array}$ \\
\hline \multirow[t]{2}{*}{ trust degree } & \multirow[t]{2}{*}{$A 5$} & direct trust degree & $B 12$ \\
\hline & & indirect trust degree & $B 13$ \\
\hline \multirow{4}{*}{$\begin{array}{c}\text { quality of products and } \\
\text { services }\end{array}$} & \multirow{4}{*}{ A6 } & products degree & $B 14$ \\
\hline & & product description fidelity & $B 15$ \\
\hline & & service attitude & B16 \\
\hline & & after-sale service & $B 17$ \\
\hline
\end{tabular}




\section{Micro Enterprises Credit Risk Decision-making Model under AHP}

\subsection{Risk Decision-making Objective Function}

For banks, micro enterprises credit risk decision-making can exploit multi-indicator linear weighted algorithm to describe and establish function. Micro enterprises credit evaluation mark:

$$
Z=\sum_{i=B_{1}}^{B_{3}} G_{A 1 i} \cdot W_{A 1 i} \cdot W_{A 1}+\sum_{i=B_{4}}^{B_{6}} G_{A 2 i} \cdot W_{A 2 i} \cdot W_{A 2}+\sum_{i=B_{7}}^{B_{9}} G_{A 3 i} \cdot W_{A 3 i} \cdot W_{A 3}+\sum_{i=B_{10}}^{B_{11}} G_{A 4 i} \cdot W_{A 4 i} \cdot W_{A 4}+\sum_{i=B_{12}}^{B_{13}} G_{A 5 i} \cdot W_{A 4 i} \cdot W_{A 5}+\sum_{i=B_{14}}^{B_{16}} G_{A 6 i} \cdot W_{A 6 i} \cdot W_{A 6} \quad \text {. Among }
$$

them $G_{A 1 i}, G_{A 2 \mathrm{i}}, G_{A 3 i}, G_{A 4 \mathrm{i}}, G_{A 5 i}, G_{A 6 i}$ represent the marks of indicators $B 1 \sim B 14$, which are subordinated to the first class indicators $A 1 \sim A 6 ; W_{A 1 i} 、 W_{A 2 i} 、 W_{A 3 i}, W_{A 4 i} 、 W_{A 5 i} 、 W_{A 6 i}$ represent the weight distribution in items which are subordinated to $A 1 \sim A 6 ; W_{A 1} 、 W_{A 2} 、 W_{A 3} 、 W_{A 4} 、 W_{A 5} 、 W_{A 6}$ represent the weight disbution in $A 1 \sim A 6$ for the overall objective, micro enterprises' credit mark.

\subsection{Data Process for Banks under AHP Method}

The qualitative and quantitative indicators have different processing methods, so evaluation standard system and grade-calculating methods need to be confirmed for each indicator, which is convenient for conprehensive calculation.

For quantitative indicators, banks can exploit average level of industry as a threshold, denoted by "60" points. If one micro enterprise' quick ratio is 0.75 and industry average quick ratio is 0.6 , then it will get $=\frac{0.75}{0.6} \times 60=75$.

For qualitative indicators, the results are divided into 5 classes: M1 excellent, M2 good, M3 medium, M4 weak, M5 bad, respectively corresponding to 90 points, 80 points, 60 points, 40 points, 20 points. Experts will convert ranks into marks.

In order to improve the rationality of micro enterprises credit risk decision-making model and reduce the influence of subjective bias from experts, a number of experts should be invited to give evaluation marks. When the raw marks are processed, obviously distint marks should be eliminated and then banks can choose average marks.

Under AHP method, in terms of matrix establishment and weight distribution, banks can choose criteria $\left(a_{i j}\right) 1 \sim 9$ as relative importance judgement standard:

Table 2. Relative importance of standard for indicators

\begin{tabular}{cc}
\hline Criteria $\left(a_{i j}\right)$ & relative importance definition \\
\hline 1 & indicator $\mathrm{i}$ and $\mathrm{j}$ are equally important \\
\hline 3 & indicator $\mathrm{i}$ is slightly more important than $\mathrm{j}$ \\
\hline 5 & indicator $\mathrm{i}$ is obviously more important than $\mathrm{j}$ \\
\hline 7 & indicator $\mathrm{i}$ is intensely more important than $\mathrm{j}$ \\
\hline 9 & indicator $\mathrm{i}$ is extremely more important than $\mathrm{j}$ \\
\hline $2,4,6,8$ & the medium judgement \\
\hline
\end{tabular}

In calculating process, summation method is used to calculate weight distribution vectors, and then formula $_{\lambda_{\max }} \approx \sum_{i=1}^{n} \frac{(A W)_{i}}{n w_{i}}$ is used to calculate $\lambda_{\max }$ for consistency test. Judgement matrix consistency test 
indicator $C . I .=\frac{\lambda_{\max }-n}{n-1}$, average random consistency indicator R.I. and consistency proportion $C . R .=\frac{C . I . I}{R . I .}$ are used. When consistency proportion $C . R .=\frac{C . I .}{R . I .}<0.1$, the consistency of judgement matrix is considered acceptable. Otherwise, the judgment matrix should be rebuilt.

In terms of total weight distribution, when the total weight distribution vector of indicators in the k-1 layer (the number: $\mathrm{k}-1), \quad W^{(\mathrm{k}-1)}=\left(w_{1}^{k-1}, \ldots, w_{k-1}^{k-1}\right)^{T}$, has been given and the weight distribution vector, $P_{j}^{(\mathrm{k})}=\left(\mathrm{p}_{i j}^{(k)}, \ldots, \mathrm{p}_{k j}^{(k)}\right)^{T}(\mathrm{j}=1,2, \ldots, \mathrm{k}-1)$, of indicators in the $\mathrm{k}$ layer (the number: $\mathrm{k}$ ) for the k-1 layer's single indicator $\mathrm{j}$ is known, and particularly, indicators in the $\mathrm{k}$ layer, which are not subordinate to indicator $\mathrm{j}$ in the $\mathrm{k}-1$ layer, the weight distribution is 0 , column vectors constitute the matrix $P^{(\mathrm{k})}=\left(\mathrm{p}_{1}^{(\mathrm{k})} \ldots \mathrm{p}_{k-1}^{(\mathrm{k})}\right)(\mathrm{k} \times \mathrm{k}-1)$, indicating indicators' weight distribution of the $\mathrm{k}$ layer for indicators in the k-1 layer. At last, the weight distribution vector of indicators in the $\mathrm{k}$ layer for the overall objective is $W^{k}=\left(w_{1}^{(k)}, \ldots, w_{k}^{(k)}\right)=P^{k} W^{k-1}$, among them

$w_{i}^{(\mathbf{k})}=\sum_{j=1}^{k-1} p_{i j}^{(\mathbf{k})} w_{j}^{k-1}(\mathrm{i}=1-\mathrm{k})$

\subsection{The Application of AHP Method in Credit Risk Decision Making Model}

According to the indicators system in this article, banks can construct a 6 order matrix, three 3 order matrixes, two 2 order matrixes and a 4 order matrix:

$C=\left[\begin{array}{llllll}1 & \frac{4}{5} & \frac{4}{5} & 1 & \frac{2}{3} & \frac{1}{2} \\ \frac{5}{4} & 1 & 1 & \frac{5}{4} & \frac{5}{6} & \frac{5}{8} \\ \frac{5}{4} & 1 & 1 & \frac{5}{3} & \frac{5}{6} & \frac{5}{8} \\ 1 & \frac{4}{5} & \frac{3}{5} & 1 & \frac{2}{3} & \frac{1}{2} \\ \frac{3}{2} & \frac{6}{5} & \frac{6}{5} & \frac{3}{2} & 1 & \frac{3}{4} \\ 2 & \frac{8}{5} & \frac{8}{5} & 2 & \frac{4}{3} & 1\end{array}\right], \quad D_{1}=\left[\begin{array}{ccc}1 & 1 & \frac{5}{4} \\ 1 & 1 & \frac{5}{4} \\ \frac{4}{5} & \frac{4}{5} & 1\end{array}\right], \quad D_{2}=\left[\begin{array}{ccc}1 & 1 & \frac{4}{5} \\ 1 & 1 & \frac{4}{5} \\ \frac{5}{4} & \frac{5}{4} & 1\end{array}\right], \quad D_{3}=\left[\begin{array}{lll}1 & 1 & \frac{4}{5} \\ 1 & 1 & \frac{4}{5} \\ \frac{5}{4} & \frac{5}{4} & 1\end{array}\right]$,

$D_{4}=\left[\begin{array}{ll}1 & 1 \\ 1 & 1\end{array}\right], \quad D_{5}=\left[\begin{array}{cc}1 & \frac{5}{4} \\ \frac{4}{5} & 1\end{array}\right], \quad D_{6}=\left[\begin{array}{cccc}1 & \frac{6}{5} & \frac{6}{5} & 1 \\ \frac{5}{6} & 1 & 1 & \frac{5}{6} \\ \frac{5}{6} & 1 & 1 & \frac{5}{6} \\ 1 & \frac{6}{5} & \frac{6}{5} & 1\end{array}\right]$

Among them ${ }^{c}$ represents the judgement matrix of $A 1 \sim A 4, D_{1} \sim D_{*}$ represent respectively the judgement matrixes for $B_{1} \sim B_{3}, B_{4}-B_{6}, B_{1}-B_{3}, B_{10} \sim B_{11}, B_{12} \sim B_{13}, B_{14} \sim B_{17}$. The weight distribution vectors, ${ }^{\lambda_{\mathrm{max}}}$ and the result of consistency test are as follows: 
Table 2. Calculating results

\begin{tabular}{ccc}
\hline weight distribution vectors & $\lambda_{\max }$ & $C . R$. \\
\hline$W_{Z}=\left(0.12464,0.15581,0.16405,0.11927^{*}, 0.18696,0.24928\right)^{T}$ & 6.00918 & $0.001457<0.1$, \\
\hline$W_{A 1}=\left(0.3571,0.3571,0.2858^{*}\right)^{T}$ & 3 & $0<0.1$ \\
\hline$W_{A 2}=(0.3077,0.3077,0.3846)^{T}$ & 3 & $0<0.1$ \\
\hline$W_{A 3}=(0.3077,0.3077,0.3846)^{T}$ & 3 & $0<0.1$ \\
\hline$W_{A 4}=(0.5,0.5)^{T}$ & 2 & $0<0.1$ \\
\hline$W_{A 5}=(0.5556,0.4444)^{T}$ & & $0<0.1$ \\
\hline$W_{A 6}=(0.2727,0.2273,0.2273,0.2727)^{T}$ & 2 & $0<0.1$ \\
\hline
\end{tabular}

Note: figures in the table with “*” contain adjustment

From Table 2, we can see the matrixes all satisfy consistency test, the weight distribution vectors of indicators of all layers for their upper objectives are $W_{Z}, W_{A 1}, W_{A 2}, W_{A 3}, W_{A 4}, W_{A 5}, W_{A 6}$. Eventually the weight distribution vector of all the secondary indicators, $B 1 \sim B 17$, for the whole objective $\mathrm{Z}$ is $W=\left(w_{1}, \ldots, w_{17}\right)^{T}$, among

them:

$$
\begin{aligned}
& w_{A 11}=0.0445, w_{A 12}=0.0445, w_{A 13}=0.0356, w_{A 24}=0.0479, w_{A 25}=0.0479, w_{A 26}=0.0599, \\
& w_{A 37}=0.0505, w_{A 38}=0.0505, w_{A 39}=0.0631, w_{410}=0.0596, w_{411}=0.0596, w_{512}=0.1039, \\
& w_{513}=0.0831, w_{614}=0.0680, w_{615}=0.0567, \\
& w_{616}=0.0567, w_{617}=0.0680 .
\end{aligned}
$$

Put evaluation marks and weight figures into objective function for calculating, then the final score of micro enterprise' credit risk assessment comes out. According to the results and corresponding credit standards, banks will determine whether to give a loan to micro enterprises.

\section{The Strategy of Big Data of Banks}

For micro enterprises credit risk decision-making of banks, the critical step is data mining. Conventional banks in terms of data's flexibility, dimensions and correlation are weaker than the big data operators, social networking sites and e-commerce platform, so it's urgent for banks to develop their own big data strategies. In the entire loan business process, sufficient data mining will make a difference in credit risk control.

Table 3. Data mining effect on micro enterprises' credit risk control

\begin{tabular}{ccc}
\hline data mining stage & mined information & risk control effect \\
\hline before the loan & financial state for micro enterprises & avoid uncollectable accounts \\
\hline before the due date & $\begin{array}{c}\text { transaction evaluation system of the Internet, } \\
\text { logistics and distribution }\end{array}$ & improve vigilance \\
\hline after due date & realizable assets state & save loss \\
\hline
\end{tabular}

\subsection{Establish the Sense of Big Data}

Banks should recognize that the future competition of financial industry is the competition in data utilzation. By optimizing the allocation of data resources and inputs on data industry, banks can use data mining tools effectively. Via data analysis and processing technology, the scattered information can be centralized, isolated information become interrelated information and worthless data turn into valuable information, achieving the optimal allocation of resources and reducing blindness of decision-making, which are a very important direction for the information construction of banks. 


\subsection{Explore a New Path for Credit Availability}

One of the main reasons why the Internet companies can develop micro enterprises credit loan business is the advantage of big data. For example, Alibaba, through customer basic information, real-time transcation information, learn the needs of micro enterprises and credit qualifications. Therefore, banks should try to "make up" this defect.

\section{1) Build Own Big Data Platform}

Now Construction Bank of China has created a "good financial Mall", build own e-commerce platform, which combine buiness with finance, making itself develop financial services on the basis of big data.

2) Strengthen Cooperation with Data Providers

Microblog has become a major platform for real-time information exchange. China Everbright Bank has carried out payment business by means of microblog, providing convenient access for users. Banks can use microblog, wechat or other social medium, break the traditional barriers between structured and unstructured data, mining user credit information. Particularly, banks should devote themselves to developing "supply chain finance", refer to the credit qualification of core enterprises, mine information about cash flow, logistics and outlook information about supply chain industry and provide credit support to micro enterprises in the chain, serving the whole supply chain to ensure its normal operation.

\subsection{Strengthen the Construction of Big Data Talents}

With the reconstruction of banks data system under the big data strategy, accordingly, they should also strengthen the construction of big data talents. Data management talents is needed to prevent Internet attacks and leakage of user privacy caused by malicious use of data resources; data mining and analytical talents should explore new data mining tools and analysis methods.

\section{Conclusion}

In the era of big data and the Internet, Internet companies have adequate advantages of data to step into the financial industry. Facing the challenges, banks can no longer stick to conventions, on the contrary, they should establish a big data strategy which will play a significant role in the micro enterprises loan risk dynamic decision-making process. From static financial data indicators system to dynamic Internet indicators system, mining information related to clients credit qualification, banks can make micro enterprises credit loan risks as low as possible. Compared to traditional credit risk decision-making mode, this mode is much cheaper, easier and more accurate.

\section{Acknowledgements}

In writing this article, I have benefited from the presence of my tutor and my classmates, they generously gave me invaluable advice. Particularly, I am grateful to my totor, professor Junxuan.Zhu. My parents took care of my life and gave me much encouragement. At last, I want to attribute my thanks to the staff in our school library for their patience and kindness.

\section{References}

He, Lijuan. (2012). Construction of Credit Evaluation System in E-commerce Environment. Southwest University of Finance and Economics, 9.

Jing, Hua. (2013). Internet Finance in the Era of Big Data. International Finance, (11). 24-25.

Sun, Hongcai, Tian, Ping, \& Wang, Lianfen. (2011). Analytic Hierarchy Process and Decision Sciences. Beijing: National Defense University Press, 39-40.

Wang, Luo. (2012). Ali Credit Loans Are Open to The General Membership. Jiangnan Newly Report, 2012-7-27.

Wang, Rui, Wu, Lifa, \& Zhang, Tingting. (2013). A Web Service Trust Computing Model Based on Ontology. Application Research of Computers, 30(7), 2077-2081.

Xu, Xiaoming, \& Li, Xiaoqing. (2006). Bank's Risk Data Mining System Based on Knowledge Management. Financial Computer, 14(10), 41-45.

Yu, Hongkai. (2013). Impact and Regulation in the Development of Internet Finance. Inner Mongolia Financial Research, (9), 8-11.

Zhao, Fuling, An, Feng, \& Zhang, Xiaofeng. (2013). Information Technology Issues Analysis of Commercial Banks in Big Data Era. Financial Theory and Practice, (10), 56-60.

Zheng, Chengman. (2013). Commercial Banks' Opportunities and Challenges in Big Data Era. Chinese Financial Computer, (7), 41-42. 